\title{
THE “NORMATIVES” CONTROLLING APPROACH IN SMES IN BAVARIA
}

\author{
Stefan Ehrnböck ${ }^{1}$, Pavel Žufan ${ }^{1}$ \\ ${ }^{1}$ Department of Management, Faculty of Business and Economics, Mendel University in Brno, Zemědělská 1, \\ 61300 Brno, Czech Republic
}

Link to this article: https://doi.org/10.11118/actaun.2021.025

Received: 24. 7. 2020, Accepted: 25. 3. 2021

To cite this article: EHRNBÖCK STEFAN, ŽUFAN PAVEL. 2021. The "Normatives" Controlling Approach in SMEs in Bavaria. Acta Universitatis Agriculturae et Silviculturae Mendelianae Brunensis, 69(2): 275-279.

\begin{abstract}
This paper analyzes the effectiveness and efficiency of the normatives' controlling against the operational and strategic controlling. The general focus in studies and focus of the controlling experts is mostly on the operational controlling. For the analysis of the normatives' controlling in Bavarian SMEs a primary research data set is used. The survey was aimed on Bavarian SME's in the machine building sector. We employ regression models for the assessment of significance of the influencing factors, which are causing the negation of the normatives' controlling. We use monthly hours worked in the normatives' controlling, percentage acceptance of the normatives' controlling, used normatives' controlling instruments and the number of employees working in the controlling department as the influencing factors. The empirical evidence shows significant results affecting Bavarian SME's - Acceptance (monthly capacity of the head of controlling department) was identified as a significant variable on a statistically significant level with the estimated coefficient of 0.217 in relation to the Hours (monthly hours of work capacity) of normatives' controlling departments, and Instruments (number of instruments used) were proved to significantly influence the Employees (number of employees in controlling department) with the coefficient of 2.099. With the growing importance of the ability of an organization to publicly demonstrate its success in reaching objectives and specifically in its societal impacts, the importance of setting normatives and their control will project into higher demands on the work capacity of the controlling departments.
\end{abstract}

Keywords: normatives' controlling, sustainability, social and environmental aspects, norms, SME

\section{INTRODUCTION}

The term "normatives' controlling" is often associated with corporate culture and its management, but this term is not limited to corporate settings. Controlling of normatives is interpreted as a periodical review of set normatives and can be considered as a part of controlling. The normatives' controlling approach is aiming on the optimal setting of the controlling systems within an organization (Osmanagić Bedenik, 2015). The general controlling systems comprise different subsystems like the operational, strategic and normatives' controlling (Śliwczyński, 2011). These subsystems and their elements support availability of information for the managers to make optimal decisions (Tamulevičiené,
2016). The general goals of a company can only be achieved if an operational, strategic and normatives' controlling exits in an organization (Gleißsner et al., 2013). Normatives' controlling though influences all processes and actions in an organization (Kärreman et al., 2013) and transfers the responsibility from the organizational system to the individuals, making them responsible for all actions and outcomes. The responsibility for the individual actions and outcomes must be independently considered from the perspective of the related corporate social responsibility, the social risks and the general activities of a human being (Rasmussen, 2011). Normatives' controlling should represent a support of strategy implementation, being a part of a general 
controlling strategy in every organization. In order to make the operational, strategic and normatives' controlling work efficiently, it is important to define the subsystems of the controlling system, terms like object, subject, functions, process, methodology and used instruments (Vuko et al., 2013). These defined compositions of the subsystems depend on the company size.

The main focus in normatives' controlling is analyzing the gap between the desired corporate culture and the existing one. This gap should be held as narrow as possible, using the normative approach (Siller, 2011). Another important field in normatives' controlling is to help to seek and maintain general contact with stakeholders and third party groups (Siller, 2011). The controlling approaches, which are developed in Germany, are different to Anglo-American frameworks, which are called Management control systems (Günther, 2013). Normatives' controlling is based on the general principles of social life. The concepts and approaches of normatives' controlling are only 20 years old. Gaubinger was the first to mention the term in 2000. He marked the general term of normatives' controlling as an approach that implies the responsibility to improve and analyze the corporate policy and the corporate culture in an organization. Gaubinger (2000) analyzed the mission statements of companies and conducted, based on these results, a targetperformance comparison of their corporate cultures.

Nowadays, a lot of different concepts and approaches to controlling are discussed in literature. The diverse concept of controlling has been widely interpreted in the German-speaking countries (Henri, 2006). The concept of controlling, according to Hirsch (2007), is the interaction between the operational and strategic controlling with all systems, subsystems, and humans in an organization. Hirsch believes that the operational controlling must be in conjunction with strategic controlling (Hirsch, 2007). According to the demographic changes in the world, the ongoing green aspects like avoiding $\mathrm{CO}_{2}$ emission, diesel scandal or avoiding plastic, normatives' controlling becomes important for all organizations. The normatives' controlling tries to reach the required efforts of every member in an organization by controlling their individual experiences and feelings, which guide their human actions (Kunda, 2006). For an operational normatives' controlling, the members in an organization must internalize the general normatives the organization values. Therefore, it is fundamental that the organizational values are defined from the business owners in SMEs (Willmot, 1993).

The main objective of this paper is to evaluate the usage of normatives' controlling in Bavarian SMEs and to formulate recommendations for these SMEs on how to proceed with their three controlling levels. We use the literature analysis for the hypothesis formulation, and we collect primary data via online survey to test the hypotheses.

\section{MATERIALS AND METHODS}

According to the literature review of the normatives' controlling, two hypotheses can be defined. The first hypotheses is formulated in the following way: "Higher acceptance of the normatives' controlling is connected with higher monthly work capacity of the normatives' controlling" and the second hypotheses as "Number of normatives' controlling instruments used is connected with the number of normatives controlling staff'. These two hypotheses are defined to evaluate the practicing of the normatives' controlling and to verify their effectiveness and efficiency against the operational and strategic controlling.

For the data evaluation of normatives' controlling in Bavarian SMEs, a survey was conducted through an online questionnaire. The selected companies have 50-200 employees and maximum annual turnover of 50 million Euro in accordance with the EU Commission definition (Eurostat, 2019). This online questionnaire includes questions on qualitative and quantitative aspects of normative controlling. 200 medium-sized companies in Bavaria were presented the questionnaire via email. The companies were randomly pre-selected from the database "Bayern International" database, an SME-database of Bavarian small and medium sized companies available at https://www.bayerninternational.de/firmendatenbank/. The selected SMEs were active in the electrical and mechanical manufacturing industry.

The questionnaire contained 8 questions for each separate controlling hierarchy, and questions regarding normatives' controlling conceptions in SMEs and instruments used in the respective companies. To ensure that the online questions are understandable for the participants, the questionnaire was tested with representatives of 5 businesses, which resulted in an adjustment of several questions to make them more understandable. Furthermore, information material about normatives' controlling has been integrated in the e-mail attachment to the online survey. The questionnaire also includes questions about the employees in the controlling departments.

For hypotheses testing the regression model and the OLS method are used. The four variables represent the influencing factors, which indicate the nature of the normatives' controlling practices. These influencing factors are selected from the survey answers of the survey participants combined with the analysis of the normatives' controlling literature. Four factors were selected as variables for regression analysis:

- Hours - hours which are worked on normatives' controlling tasks in a 40-h-week month.

- Acceptance-estimated percent (0-100\%) capacity of the head of controlling department. 
- Employees - number of currently employed people in the controlling department of the surveyed business.

- Instruments - number of weekly used controlling instruments estimated from the head of controlling department.

In the last step a robustness analysis with the quantile regression method is practiced. In this method, median represents the focus and not the average, therefore it can provide a good robustness check for this data. Gretl software was employed, significance level was set to 0.05 .

\section{RESULTS}

For testing the first hypothesis there are estimated linear regression models with dependent variable Hours. As the independent variables we use Acceptance, Instruments and Employees. Resulting models are summarized in Tab. I.

Model 1-1 starts with all independent variables. This model is of reasonable quality of the regression with adjusted coefficient of determination of 0.938. The only significant variable is Acceptance. After elimination of insignificant variables, we obtain Model 1-2, where adjusted coefficient of determination lowers only slightly to 0.929. The estimated coefficient of Acceptance moves from 0.199 to 0.217 , which points to stability of the regression model. For testing the robustness, Model 1-3 was estimated by quantile regression method. The Acceptance remains significant with similar value of the regression coefficient, which can be assessed as sufficient robustness check.

The second hypothesis is tested via estimated linear regression models with dependent variable Employees. As the independent variables we use Acceptance, Instruments and Hours. Resulting models are summarized in Tab. II. The quality of Model 2-1, which contains all independent variables given by adjusted determination coefficient equal 0.900 is still high. significant. Only Instruments variable is significant here; after elimination of insignificant variables, we obtain Model 2-2 with adjusted determination coefficient equal to 0.905 . Regression coefficient of Instruments moves from 1.862 to 2.099. After providing Model 2-3 based on quantile regression method, we can confirm both stability and robustness of the estimated models.

Even though it seems surprising, that there was confirmed a relation of the number of employees in a controlling department, and the number of instruments used, no statistically significant relation was found in the case of the hourly capacity spent on normatives' controlling. This can, though, be relatively simply explained through the apparent "help" of the used instruments, which simplify the tasks of the controlling staff.

Resulting Model 2 resp. Model 2-3 can be used as confirmation of our hypotheses. In both cases, direct significant dependence is revealed.

\section{DISCUSSION}

In past studies by Deloitte 2008, it could be seen that the operational controlling dominates in SMEs in Germany (Deloitte-Mittelstandsinstitut, 2008). In these studies of Prof. W. Becker there was only evaluated the use of operational controlling in SMEs in Germany. When searching for relevant studies, no relevant studies could be found paying attention to an evaluation of strategic or normatives' controlling in German SMEs. No studies in the normatives' sector have been conducted in the past and additionally low number of normatives-related literature exists in general.

I: Regression models with dependent variable Hours

\begin{tabular}{|c|c|c|c|c|c|c|}
\hline Variable & Coefficient & p-value & Coefficient & p-value & Coefficient & $\mathrm{p}$-value \\
\hline Acceptance & 0.199 & $<0.001$ & 0.217 & $<0.001$ & 0.2 & 0.024 \\
\hline Instruments & 0.348 & 0.173 & $\mathrm{x}$ & $\mathrm{x}$ & $7.21 \mathrm{e}-13$ & 1 \\
\hline
\end{tabular}

II: Regression models with dependent variable Employees

\begin{tabular}{lcccccc}
\hline & \multicolumn{2}{c}{ Model 2-1 } & \multicolumn{2}{c}{ Model 2-2 } & \multicolumn{2}{c}{ Model 2-3 } \\
\cline { 2 - 7 } \multicolumn{1}{c}{ Variable } & Coefficient & p-value & Coefficient & p-value & Coefficient & p-value \\
\hline Constant & -0.264 & 0.243 & -0.065 & 0.745 & $-4.09 \mathrm{e}-10$ \\
Acceptance & 0.039 & 0.392 & $\mathrm{X}$ & $\mathrm{x}$ & $1.61 \mathrm{e}-10$ & 0.314 \\
Hours & -0.016 & 0.942 & $\mathrm{x}$ & $\mathrm{x}$ & $-2.52 \mathrm{e}-10$ & 0.520 \\
Instruments & 1.862 & $<0.001$ & 2.099 & $<0.001$ & 2 \\
\hline
\end{tabular}


Acceptance and the number of used normatives' controlling instruments in SMEs have had a large impact on hours spent in noermatives' controlling. On the other hand, number of employees did not prove to be statistically significant in relation to the ours spent on normatives' controlling - as well as the level of acceptance did not significantly project into the number of employees working on the normatives' controlling related tasks. Without the acceptance of management, normatives' controlling will further be neglected, and only operational controlling will be practiced (Deloitte Mittelstandsinstitut, 2008).

The fact that there exists a little research in the field of normative controlling made it necessary to conduct an own study with an own developed questionnaire. In most SMEs in the survey there is practiced an old-fashioned controlling with "traditional" instruments and conceptions. Another general issue is that the concept of controlling in Germany has been only applied for some 20-30 years. But without a state of the art controlling with up-to-date conceptions and instruments no controlling can work effectively nor efficiently.

The ongoing globalization, the integration of sustainability principles in production like avoiding water pollution or reducing of use of plastics will force companies to practice more normative aspects. As the general and business environment continuously changes, also the "old-fashioned" pure data-based controlling used 20 years ago needs to reflect these changes and needs a more "state of the art” approach. Thus, the normatives' approach will be one of the most important management approaches and tools for SMEs and generally for all companies in the next 10 years.
Aspects like corruption as seen in the diesel scandal or mismanagement add more urgency to deal with the related topics, like normatives' controlling, as well. Nowadays, the stakeholder interests and third parties' interests are more important to respect than 20 or 30 years ago. Therefore, the general controlling must integrate more social, environmental and health-related management instruments and aspects in their organization.

Another important aspect is that without the recognition of all three levels of the controlling hierarchy, no controlling makes sense. Practicing operational controlling only and concentrating only on pure data with no strategic or normative aspects will lead to the lack of sustainability and lack of long-term orientation. On the top of each controlling level must be the normatives' controlling. The executive hierarchy is the operational controlling at the bases, which supports the normatives' and strategic controlling. All three dimensions must be practiced with relevant efforts and attention. Neglecting one level of controlling influences fundamentally the other two levels.

Potential weaknesses of this presented research could be that the sample size of 200 companies in the survey is not completely representative for all SME branches. But even with this limitation, it represents a good starting point for further studies done in a bigger scale - either towards a verification of the findings of this research or towards its extension with other potential viewpoints and analyses.

\section{CONCLUSION}

The paper presents research aiming on the research gap identified in the past controlling studies in SMEs in Germany, which an be characterized as a lack (or almost none) attention paid to the normatives' controlling. No data about sudies on normatives' controlling could have been found. Based on the analysis of the literature and the previous controlling-related studies, two hypotheses related to the normatives' controlling were formulated.

Based on the results of the regression analysis, the hypothesis "Higher acceptance of the normatives' controlling is connected with higher monthly work capacity of the normatives' controlling" has been confirmed on the significance level of 0.05 (p-value of 0.024, actually). In this regard, the influence of the number of instruments and number of employees did not show statistical significance.

The second hypothesis "Number of normatives' controlling instruments used is connected with the number of normatives' controlling staff" has also been confirmed (even on the level of 0.001)), but no statistically significant connection of the number of employees in controlling departments was identified in case of the acceptance and, slightly surprisingly, also hourly capacity of the controlling staff.

Given the results of the survey of literature in combination with the research done in this paper, the SMEs should increase the work capacity ("number") of their general controlling staff, and should be more open in terms of the normatives' controlling and generally the recent concepts and approaches to controlling. Approaches building on setting and controlling normatives will be gaining on importance with the growing interest in operations of all organizations and government units related to not only their "internal", but also societal impacts and interrelations. 


\section{REFERENCES}

EUROSTAT. 2019. EU-definition of SMEs. Eurostat. [Online]. Available at: https://ec.europa.eu/eurostat/ de/web/structural-business-statistics/structural-business-statistics/sme [Accessed: 2019, June 23].

GAUBINGER, K. 2000. Strategic Marketing Controlling for small and medium sized companies [in German: Strategisches Marketing Controlling für KMU. Basis für den Erfolg im EU-Binnenmarkt]. Wiesbaden: Deutscher Universitätsverlag.

GLEIßNER, W., HELM, R. and KREITER, S. 2013. Measurement of competitive advantages and market attractiveness for strategic controlling. Journal of Management Control, 2013(24): 53-75.

GUENTHER, T. 2013. Conceptualisations of controlling in German-speaking countries: analysis and comparison with Anglo-American management control frameworks, Metrika: International Journal for Theoretical and Applied Statistics, 23(4): 269-290.

HENRI, J.-F. 2006. Management control systems and strategy: A resource-based perspective. Accounting, Organizations and Society, 31(6): 529-558.

HIRSCH, B. 2007. Péter Horváth Controlling. Controlling \& Management. 51(2): 144-144.

KUNDA, G. 2006. Engineering Culture, Control and Commitment in a High-Tech Cooperation. Revised Edition. Philadelphia: Temple University Press.

OSMANAGIĆ BEDENIK, N. 2015. The challenge of controlling. International Journal of Industrial Engineering and Management, 6(4): 153-163.

ROMAN, C., ROMAN, A.-G., MEIER, E. 2014. Controlling in the $3^{\text {rd }}$ Millennium. Review of General Management, 20(2): 43-66.

SILLER, H. 2011. Normatives' Controlling [in German: Normatives Controlling]. UTB, Wien: Facultas Verlag.

ŚLIWCZYŃSKI, B. 2011. Operational controlling - a tool of translating strategy into action. Scientific Journal of Logistics, 7(5): 45-59.

TAMULEVIČIENĖ, D. and SUBAČIENĖ, R. 2017. Systematization of functions of controlling as a management system oriented towards increasing value: theoretical framework. ЭТАП, 5: 67-76.

VUKO, T. and OVJAN, I. 2013. Controlling and business efficiency. Croatian Operational Research Review, 2013(4): 44-52.

WILLMOTT, H. 1993. Strength Is Ignorance, Slavery Is Freedom: Managing Culture in Modern Organizations. Journal of Management Studies, 30(4): 515-552.

Contact information

Stefan Ehrnböck: Ehrnboeck@gmx.net 
